\title{
Fungal elimination of 2,4,6-trinitrotoluene (TNT) from the soils
}

\author{
Lali Kutateladze ${ }^{1 \star}$, Nino Zakariashvili ${ }^{1}$, Izolda Khokhashvili ${ }^{1}$, Maya Jobava ${ }^{1}$, Tinatin Alexidze ${ }^{1}$, \\ Tamar Urushadze ${ }^{1}$ and Edisher Kvesitadze ${ }^{2}$
}

\begin{abstract}
The analysis of microscopic fungi collection created at theDurmishidze Institute of Biochemistry and Biotechnology revealed 107 strains assimilating 2,4,6-TNT (2,4,6-trinitrotoluene) belonging to the different fungal genera. The strains have been isolated from the polluted areas adjacent to the military grounds and industrial waste waters. It has been shown TNT is degraded most actively by strains belonging to the following genera: Trichoderma, Aspergillus, Mucor and Trichoderma. Optimal cultivation conditions for highly active strains -the destructors of TNT have been revealed.

It has been established that the carbon skeleton of TNT being utilized by the mentioned strains undergoes biotransformation. The existence of radioactive intermediates of biotransformation, organic acids (70-90\%) and amino acids (10-30\%) have been detected in liquid culture. Radioactive label of $1-{ }^{14} \mathrm{C}-\mathrm{TNT}$ is mostly found in fumaric acid, which is known as one of the main products of benzene biotransformation and further conversion into succinic acid.

Remediation level of TNT-contaminated red and black soils treated by the most active strains Aspergillus nigerN2-2 and Mucor sp. T1-1 have been studied under laboratory and field conditions. Cultivation of the above mentioned strains under laboratory conditions in sterile, black and red soils for 30 days at $30^{\circ} \mathrm{C}$ allowed decreasing the content of TNT in black soil to the residual, and in red soil - to 15\%; cultivation of Aspergillus niger N2-2 decreased the amount of TNT in black soil to 11 and in red soil to $21 \%$. Under field conditions, TNT degradation level in contaminated soils by naturally existing micro flora during 100 days was equal to $40-50 \%$, and in the case of additional introduction of both fungal strains, TNT-destructors reached $80 \%$.
\end{abstract}

Keywords: microscopic fungi, destructor strains, organic toxicant, 2,4,6-trinitrotoluene (TNT), bioremediation

${ }^{1}$ Agricultural University of Georgia, S.Durmishidze Institute of Biochemistry and Biotechnology, University Campus of Digomi, David Agmashenebeli Alley 240, Tbilisi 0159, Georgia.

${ }^{2}$ Georgian Technical University, Tbilisi 0175 , Kostava str. 77

*Corresponding author: L. Kutateladze E-mail: I.kutateladze@agruni.edu.ge

DOI: 10.2478/ebtj-2018-0007

\section{Introduction}

Nitroaromatic, polycyclic and polychlorinated compounds of dibenzo-dioxin group are characterized by high and long-term toxicity (1). TNT (2,4,6-trinitrotoluene),an explosive listed in all countries military arsenal, belongs to nitro aromatic compounds and has clearly defined toxic effects on all biological objects and prolonged stability under natural conditions; penetrates into the human organism via gastrointestinal tract, skin and lungs and accumulates in the liver, kidneys and adipose tissues (2). TNT belongs to carcinogenic toxicants. Due to low water solubility, TNT occurs in soil mainly in the form of crystals and is washed gradually into ground waters. To create the strategy of low water solubility compounds elimination from the soil first of all dioxins having extremely low water solubility and high sorption properties should be mentioned. Compounds similar to dioxins are not capable to migrate vertically even in sandy soils; however, according to many years' investigations, it has been established that dioxins are able to penetrate into the certain layers and maintain toxicity of soil for a rather long time $(3,4)$.

Microorganisms are considered to play an important role in cleaning of soils and waters contaminated with organic toxicants. Unlike non-biological technologies of environmental cleaning, bioremediation is recognized as a cost-effective and comprehensive 
technology. By applying this method, maximal cleaning and long-term protection of the environment without breach of ecological balance can be achieved.

Nowadays, strains-destructors of organic toxicants mainly belonging to bacteria and basidial fungi (white-rot fungi) have been studied $(5,6)$. In comparison with other taxonomic groups of microorganisms, the detoxification potential of microscopic fungi is investigated in a less extent; however, according to the data of last decade, representatives of some genera of microscopic fungi, in particular, zygo- and deuteromycetes also displayed an ability to decompose 2,4,6-TNT and other toxic compounds and mineralize them (7).

The production and use of TNT for military purpose has led to its wide distribution. Being one of the most toxic explosives TNT is classified as a carcinogenic substance of group C. Microbial transformation of TNT begins with reduction of one of the nitro groups. The goal of the present work is the revelation of potential of some microscopic fungal strains to assimilate TNT and on the base of these data creation of ecobiotechnology for their application in remediation of soils polluted by TNT.

\section{Materials and Methods}

For the selection of microscopic fungi strains-destructors of 2,4,6-TNT, from the collection of microscopic fungi representativesof the following genera: Aspergillus, Penicillium, Mucor, Fusarium, Trichoderma, Rhizopus, Botrytis, Altenaria, Cladosporium and Trichothecium, isolated from different polluted regions and available at the Durmishidze Institute of Biochemistry and Biotechnology of Agricultural University of Georgia have been used. To evaluate the degradation potential of the above mentioned genera, previously chosen cultures have been studied $(8,9)$.

After primary isolation of microflora from the soils and their purification, strains were identified according to the manuals of microscopic fungi $(10,11,12)$.

At first, in order to select concentrations of organic toxicants TNT content was determined in experimental soil sampling sites. Organic compounds from soil samples have been extracted by methanol. TNT content in the extract was determined by reversible-phase high effective liquid chromatography on the column BondaPacC ${ }_{18}(15 \mathrm{~cm} 4.6 \mathrm{~mm}$, size of particles $-5 \mu \mathrm{m})$ under the following conditions: system of solvents - methanol : water, at the volume ratio $90: 10$, flow rate $-1.0 \mathrm{ml} / \mathrm{min}$. Detection - at $254 \mathrm{~nm}$, retention time of TNT - $12.5 \mathrm{~min}$. It was found that the content of TNT in soils much exceeded permissible limit and was equal up to $5 \mathrm{mg} / \mathrm{kg}$, Ecotoxicological index of TNT by means of quantitative assessment of ecotoxicological risk of contaminated soils is equal to $2 \mathrm{mg} / \mathrm{kg}$ (13).

For the cultivation of microscopic fungi, the following nutrient media were used:

1. Czapek's modified medium \#1, \% glucose $-2,0 ; \mathrm{NaNO}_{3}-$ $0,91 \mathrm{KH}_{2} \mathrm{PO}_{4}-0,1 ; \mathrm{MgSO}_{4} \times 7 \mathrm{H}_{2} \mathrm{O}-0,05 ; \mathrm{KCl}-0,05 ; \mathrm{FeS}-$ $\mathrm{O}_{4} \times \mathrm{H}_{2} \mathrm{O}-0,002$, agar $-2,0$ (pH-6.0)

2. Czapek's modified medium \# $1^{*}, \% \mathrm{NaNO}_{3}-0,91 \mathrm{KH}_{2} \mathrm{PO}_{4}-$
0,$1 ; \mathrm{MgSO}_{4} \times 7 \mathrm{H}_{2} \mathrm{O}-0,05 ; \mathrm{KCl}-0,05 ; \mathrm{FeSO}_{4} \times \mathrm{H}_{2} \mathrm{O}-0,002$, TNT (different concentration ); agar $-2,0$ ( $\mathrm{pH}-6.0)$.

3. Czapek's modified liquid medium \#2, \% glucose - 3,0; $\mathrm{NaNO}_{3}-0,91 ; \mathrm{KH}_{2} \mathrm{PO}_{4}-0,1 ; \mathrm{MgSO}_{4} \times 7 \mathrm{H}_{2} \mathrm{O}-0,05 ; \mathrm{KCl}-$ 0,$05 ; \mathrm{FeSO}_{4} \times \mathrm{H}_{2} \mathrm{O}-0,002$, malt seedlings $-2 \mathrm{~g} / 100 \mathrm{ml},(\mathrm{pH}-$ $6.0-6.5)$.

4. Czapek's modified liquid medium $\# 22^{*}, \% \mathrm{NaNO}_{3}-0,91$; $\mathrm{KH}-$ ${ }_{2} \mathrm{PO}_{4}-0,1 ; \mathrm{MgSO}_{4} \times 7 \mathrm{H}_{2} \mathrm{O}-0,05 ; \mathrm{KCl}-0,05 ; \mathrm{FeSO}_{4} \times \mathrm{H}_{2} \mathrm{O}$ - 0,002, TNT (different concentration); malt seedlings 2g/100 ml, (pH-6.0 -6.5).

In order to receive biodegradable mass of microorganisms, cultures were grown on solid agar medium \#1 and medium $\# 1^{*}$ containing different concentrations of TNT (100 mg/l, 200 $\mathrm{mg} / \mathrm{l}, 300 \mathrm{mg} / \mathrm{l}, 400 \mathrm{mg} / \mathrm{l})$.

Conidial suspension of cultures grown on solid nutrient medium were used an inocula Cultivation was conducted at 28$30^{\circ} \mathrm{C}$ for 10 days. Growth of microscopic fungi was analyzed on $3^{\text {rd }}, 5^{\text {th }}, 7^{\text {th }}$ and $10^{\text {th }}$ days. The capability of microscopic fungi to apply TNT from the nutrient medium as a sole source of carbon and nitrogen has been studied. TNT was introduced into the medium in concentration $200 \mathrm{mg} / \mathrm{l}$. Growth intensity of cultures on solid nutrient medium was estimated visually by 3 point system: + poor growth, ++ moderate growth, +++ good growth.

In order to determine the amount of 2,4,6-TNT assimilated by fungi, deep cultivation of selected strains in Czapek's liquid modified medium \#2 and medium $\# 2^{*}$ was conducted in 750 $\mathrm{ml}$ Erlenmeyer flasks. The cultures were incubated on a rotary shaker at $200 \mathrm{rpm}$, at $30^{\circ} \mathrm{C}$ for 72 hours and the amount of residual TNT was determined (14). Intermediates and final products of TNT conversion was determined by introducing into nutrient medium $\left(1-{ }^{14} \mathrm{C}\right)$-trinitrotoluene as a component of nutrient medium $\# 2^{*}$.

In order to establish the efficacy of TNT conversion highly active strains of microscopic fungi were inoculated into the liquid medium with $\left(1-{ }^{14} \mathrm{C}\right)$-trinitrotoluene as a sole source of carbon. Labeled $\left({ }^{14} \mathrm{C}-\mathrm{TNT}\right)$ was introduced in Czapek's modified liquid medium under sterile conditions (concentration 200 $\mathrm{mg} / \mathrm{l}$; specific activity - $500 \mathrm{~Bq} / \mathrm{min}$ ). Cultivation was conducted on temperature controlled shaker $(180 \mathrm{rpm})$ for 5 days at $30-40^{\circ} \mathrm{C}$ in 750 Erlenmeyer flasks. In parallel, surface growth of cultures was carried out for two weeks under the same conditions. After completion of cultivation, biomass was removed by centrifugation (5000 rpm for 10 minutes). To remove adsorbed labeled $\left({ }^{14} \mathrm{C}\right)$ compounds, the pellet was washed with distilled water, dried at $60{ }^{\circ} \mathrm{C}$ and weighed. For qualitative determination of certain compounds from culture liquid paper chromatography method was used. For isolation of organic acids solvent system - sulphuric ether [diethylether] : formic acid : water, at the ratio 140:2:18, and for separation of sugars and amino acids - pyridine : ammonia : acetone, at the ratio -70 : $30: 20$ were used.

The radioactivity of biomass, culture liquid and their fractions was determined on scintillation counter - LKB 1211 Rackbeta at efficiency $95 \%$. 


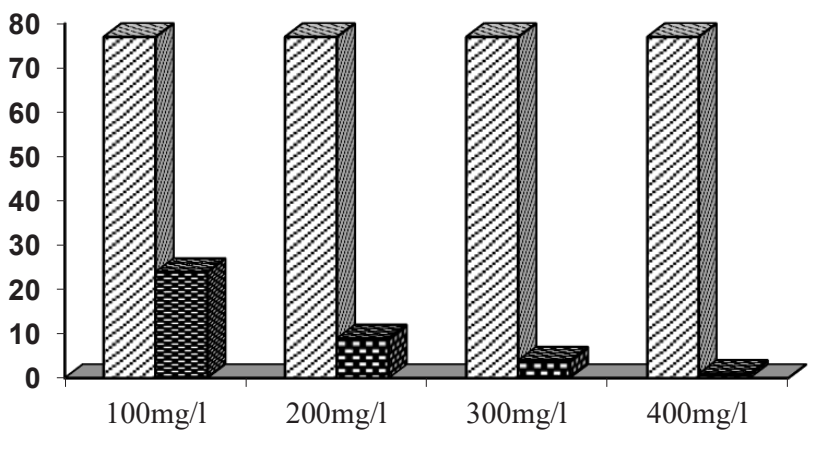
@General number of studied strains

Number of strains grown on different concentrations of TNT

Figure 1. Microscopic fungi growth potential on the media containing different concentrations of TNT.

The level of TNT degradation was studied in black and red soils under laboratory sterile and modeling conditions. $200 \mathrm{mg}$ of TNT was artificially introduced per $\mathrm{kg}$ of soil. The fungi were incubated in Petri dishes, at $35-40^{\circ} \mathrm{C}$ for 30 days, containing 25 $\mathrm{g}$ of sterile soil and $5 \mathrm{mg}$ of TNT. Under field conditions, experiments were conducted on no sterile soil, on the area of $0.5 \mathrm{~m}^{2}$, starting from the end of March till July.

Residual TNT was removed from soils by 3 -fold extraction by methanol and according to residual amount the level of TNT transformation/biodegradation was determined.

\section{Results}

\section{Selection of strains actively degrading TNT}

For the selection of fungi strains the most actively degrading TNT, 107 cultures of microscopic fungi being isolated from chemically polluted military grounds and industrial wastewaters, have been used.

Based on the 20 years experience of the authors, freshly isolated and collection strains representing the following genera Aspergillus, Trichoderma and Mucor were recognized by ability for TNT degradation. Additionally, according to the data of recent years, some strains of these genera have feature of TNT assimilation (6). At first, screening was conducted on Czapek's solid modified medium \#1 with different concentrations of TNT (100 mg/l; $300 \mathrm{mg} / \mathrm{l}, 400 \mathrm{mg} / \mathrm{l}$ ) as a sole source of carbon (these concentrations exceed TNT permissible concentration).
According to the experimental data, it has been shown that 24 among initially taken 107 strains grew well at low concentration of TNT (100 mg/l), 9 cultures - at $200 \mathrm{mg} / \mathrm{l}, 4$ cultures at higher TNT concentration $(300 \mathrm{mg} / \mathrm{l})$ and only 1 culture grew at the concentration $400 \mathrm{mg} / \mathrm{l}$ (Fig. 1).

As the purpose was the quantitative assimilation of TNT by fungal strains it was found that 9 cultures expose moderate and good growth in the presence of TNT, namely: Mucor sp. SH 6-3,Mucor sp. T1-1, Aspergillus niger N2-2; Aspergillus niger K3-5, Trichoderma viride N1-9,Trichoderma sp. N2-6, Trichotecium sp.S1-6,Penicillium sp. N-2,Fusarium monoliforma S2-6.

In case of TNT increased concentrations (from $200 \mathrm{mg} / \mathrm{l}$ $400 \mathrm{mg} / 10$ ), morphological characters of selected strains had the following changes: Mucor sp. T1, cotton-like colony gradually transformed into the leather-like one. At high concentration of TNT, circumferential rings (supposedly, induced mutation) were formed around the colonies of Fusarium monoliforma S26 , and the pigmentation was bright; colony growth was hindered in the case of Aspergillus niger K3-5 and Trichoderma viride N1-9; however, in both cases, color and sporogenesis were maintained.

In order to select active strains, destructors of TNT, toxicant was introduced into the solid medium together with glucose and as a sole source of carbon. In the nutrient liquid medium, glucose together with TNT was added with the aim to expose initial growth activity of strains. Deep cultivation

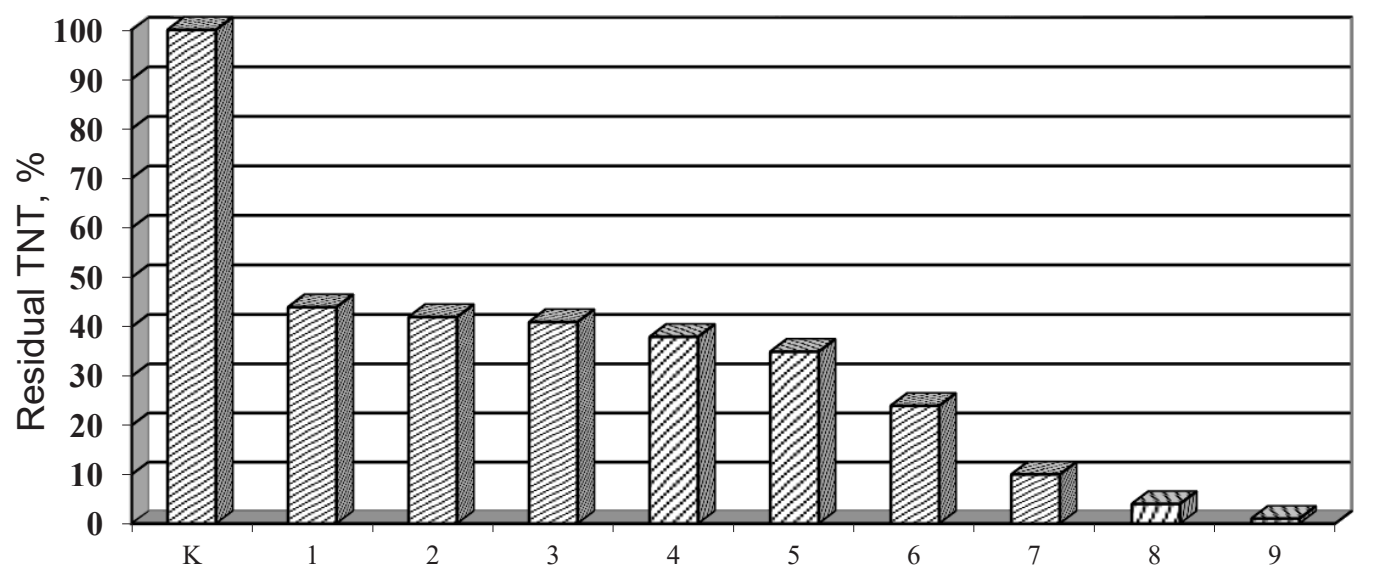

Figure 2. Strains potential to transform TNT.
K. Control $100 \%$

1. Trichoderma viride N1-9

2. Trichotecium sp. S1-6

3. Mucor sp. SH 6-3

4. Penicillium sp. $\mathrm{N}-2$

5. Fusarium monoliforma S2-6

6. Aspergillus niger $\mathrm{K} 3-5$

7. Aspergillus niger N2-2

8. Trichoderma sp. N2-6

9. Mucor sp. T 1-1 


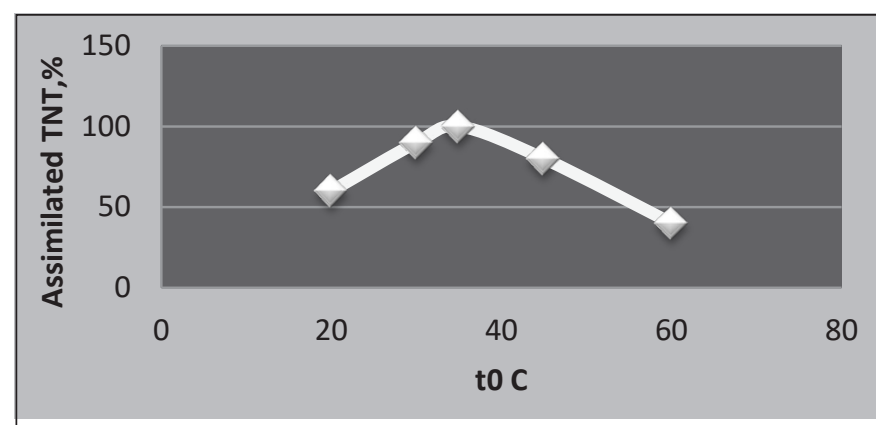

a) Strain Aspergillus niger N2-2

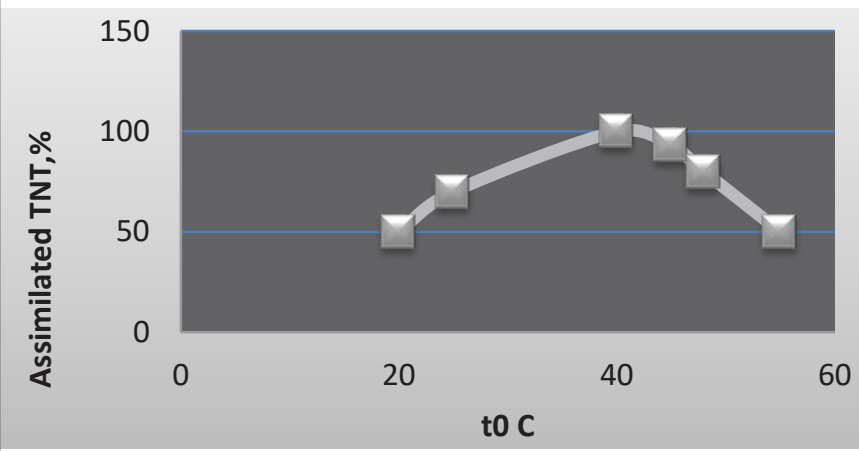

b) Strain Mucor sp. T1-1

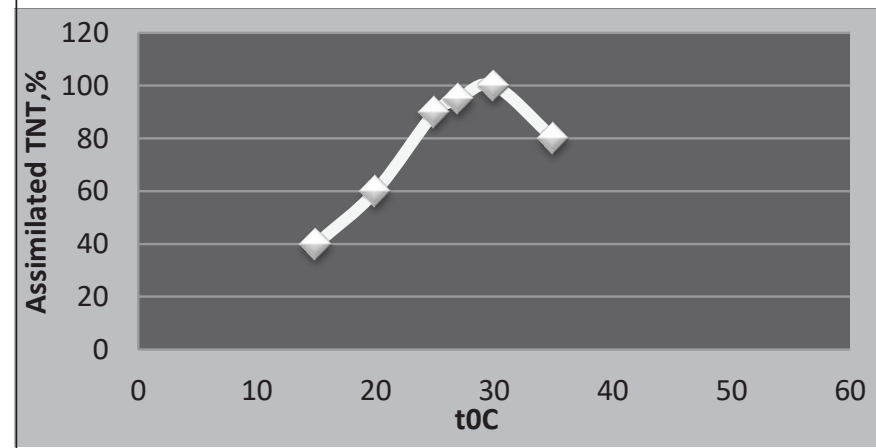

c) Strain Trichoderma sp. N2-6

Figure 3. Degradation of TNT at different temperatures by microscopic fungi.

was conducted in 750-ml Erlenmeyer flasks, on a shaker at $200 \mathrm{rpm}$, for 72 hours. Microscopic fungi were grown in the liquid medium \#2, conidial suspension of 10-day cultures were taken as inocula. The amount of residual TNT in culture liquid was determined under the strong alkaline conditions $(\mathrm{pH}>11)$. The appropriated nutrient medium in the presence of 2,4,6-TNT without inoculation of culture was considered as control containing $100 \%$ of initial TNT. Pure nutrient medium was control sample.

The amount of residual TNT indicates degradation potential of microscopic fungi carried out at these particular experimental conditions. Results are given in Fig. 2.

\section{Selection of growth conditions}

Since the metabolic activity of microorganisms significantly depends on cultivation conditions, optimal temperature, $\mathrm{pH}$ and duration of cultivation. From the point of view of TNT

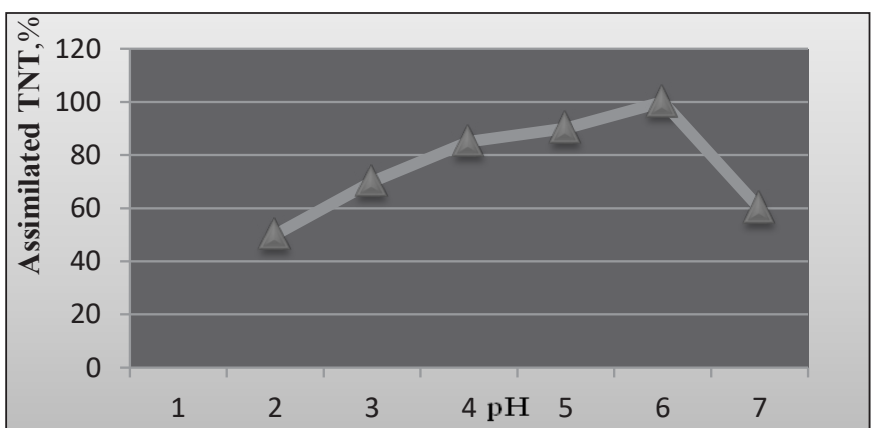

a) Strain Aspergillus niger N2-2

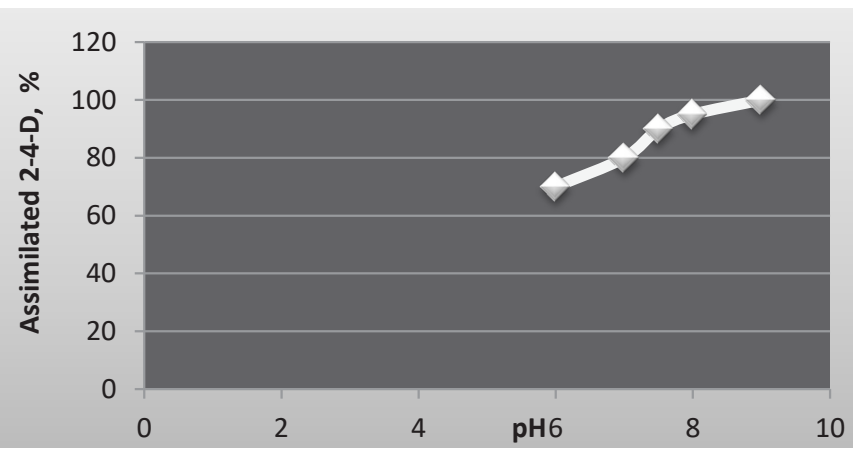

b) Strain Mucor sp. T1-1

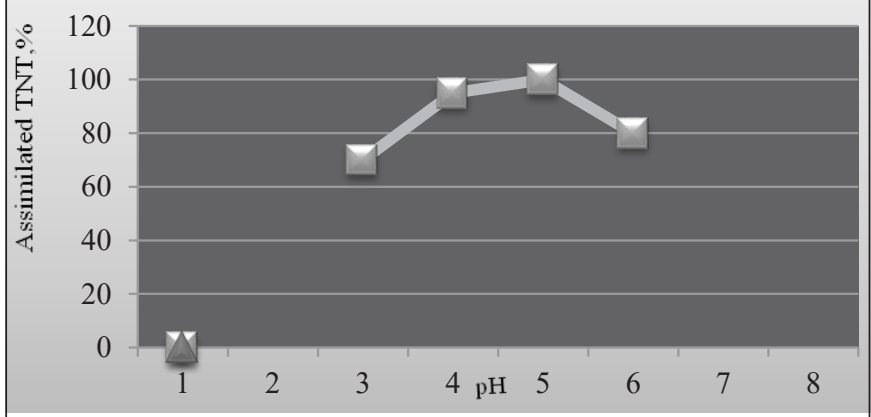

c) Strain Trichoderma sp. N2-6

Figure 4. Transformation of TNT at different $\mathrm{pH}$ values by microscopic fungi.

assimilation the optimal temperature for the deep cultivation of selected strains - Aspergillus niger K 3-5, Mucor sp. T1-1, Trichoderma sp. N2-6 and Aspergillus niger N2-2 was conducted between $20^{\circ} \mathrm{C}$ and $50^{\circ} \mathrm{C}$, at intervals of $5^{\circ} \mathrm{C}$. All three strains are typical mesophiles with the optimum of growth and TNT degradation at temperatures between $30-40^{\circ} \mathrm{C}$. The results are shown in Fig. 3a, 3b and 3c.

Maximal degradation of TNT (decomposition) is achieved by cultivation of microscopic fungi Aspergillus niger K3-5 and Aspergillus niger $\mathrm{N} 2-2$ at $35^{\circ} \mathrm{C}$ (Fig. 3a). The strain Mucor sp.T11 utilizes maximal amount of TNT at $40^{\circ} \mathrm{C}$ (Fig. 3b), Trichoderma sp.N2-6 - at $30^{\circ} \mathrm{C}$ (Fig. 3c). Acidity of reaction mixtures significantly determines metabolic activity of microscopic fungi strains. Aspergillus niger K3-5and Aspergillus niger N2-2 maximally assimilate TNT at pH 6.0 (Fig. 4a), Mucor sp.T1-1 at pH 9.0 (Fig.4b) (almost by 100\%) and Trichoderma sp.N26 - at pH 5.0 (Fig 4c). 
Table 1. The amount of $\left(1-{ }^{-14} \mathrm{C}\right)-\mathrm{TNT}$ detected in fungi biomass, in $\%$

\begin{tabular}{|l|c|c|c|}
\hline Culture & Nutrient medium \#2 & Biomass, $\mathrm{mg}$ & Total radioactivity of biomass, in \% \\
\hline Mucor sp. T1-1 & Czapek's medium & 29 & 53.6 \\
\hline Trichoderma sp. N2-6 & Czapek's medium & 25 & 51.9 \\
\hline Aspergillus niger N2-2 & Czapek's medium & 27 & 52.9 \\
\hline
\end{tabular}

Table 2. Main products of biotransformation of $\left(1-{ }^{14} \mathrm{C}\right)-$ Trinitrotoluene in culture liquid

\begin{tabular}{|l|c|c|}
\hline \multirow{2}{*}{ Strain } & \multicolumn{2}{|c|}{ Radioactivity, in\% } \\
\cline { 2 - 3 } & Organic acids & Amino acids \\
\hline Mucor sp.T1-1 & 72.2 & 27.8 \\
\hline Trichoderma sp. N2-6 & 77.4 & 22.6 \\
\hline Aspergillus niger N2-2 & 89.8 & 10.2 \\
\hline
\end{tabular}

\section{Assimilation of (1-14C)-TNT by microscopic fungi}

In spite of some datathe mechanism of explosive degradation by fungi has not been completely investigated (5). In our turn order to investigate the products of $\left(1-{ }^{14} \mathrm{C}\right)$-trinitrotoluene transformation and distributionthe strains of the different genera - Mucor sp.T1-1, Aspergillus niger N2-2 and Trichoderma sp. N2-6, were applied. Surpassingly, strains of various genera microscopic fungi convert $1{ }^{14} \mathrm{C}$ TNT with different intensities. Under the conditions of 5-day exposition with radioactive label, more than half of radioactivity of assimilated by strains $1-{ }^{14} \mathrm{C}$-TNT remained in the biomass. Results are given in Table 1. Content of $14 \mathrm{C}$ in soluble fractions is presented in
Table 2. Distribution of radioactivity in formed organic acids (Table 3) and amino acids (Table 4) has been established.

Radioactive organic acids containing $70-90 \%$ of total radioactivity and amino acids with $10-30 \%$ of radioactivity have been detected in culture liquid.

\section{Laboratory and field experiments}

The two active fungi strains of different genera - Aspergillus niger N2-2 and Mucor sp. T1-1 were chosen for remediation of TNT-contaminated soils under the natural modeling conditions.

Laboratory experiments were conducted in Petri dishes containing $25 \mathrm{~g}$ of black and red soils (widely spread in western and eastern Georgia) and contaminated with $200 \mathrm{~g} / \mathrm{kg}$ TNT. The strain Aspergillus niger N2-2 was introduced in the amount of $8.5 \times 10^{6} \mathrm{CFU}$ (Colony Forming Unit) in terms per $1 \mathrm{~g}$ of soil, and Mucor sp. T1-1 - in the amount of $7.5 \times 10^{5} \mathrm{CFU}$. Black and red soils contaminated with the same amount of TNT without introduction of microorganisms served as control. Cultures were incubated at $30^{\circ} \mathrm{C}$, with duration of the experiment for 30 days. Every $10^{\text {th }}$ day quantitative changes in CFU and the amount of residual TNT were tested. The results are presented in Table 5 and Fig. 5.

Table 3. Distribution of radioactivity of $\left(1-{ }^{14} \mathrm{C}\right)$-trinitrotoluene transformation by fungi strains among organic acids

\begin{tabular}{|c|c|c|c|c|c|c|c|}
\hline \multirow[b]{2}{*}{ Strain } & \multirow{2}{*}{$\begin{array}{l}\text { Total radioactivity } \\
\text { in } \% \text {, of low } \\
\text { molecular } \\
\text { compounds } \\
\text { fraction }\end{array}$} & \multicolumn{6}{|c|}{ Distribution of radioactivity in organic acids, in \% } \\
\hline & & $\begin{array}{c}\text { Fumaric } \\
\text { acid }\end{array}$ & $\begin{array}{c}\text { Succinic } \\
\text { acid }\end{array}$ & $\begin{array}{l}\text { Glycolic } \\
\text { acid }\end{array}$ & $\begin{array}{l}\text { Citric } \\
\text { acid }\end{array}$ & Malic acid & Unknown \\
\hline Mucor sp.T1-1 & 72.0 & 86.6 & 4.1 & 2.8 & 2.7 & 1.8 & 2.0 \\
\hline Trichoderma sp. N2-6 & 77.4 & 91.8 & 4.0 & 1.5 & 1.1 & 0.8 & 0.8 \\
\hline Aspergillus niger N2-2 & 89.8 & 88.8 & 3.3 & 3.7 & 1.2 & 0.7 & 2.3 \\
\hline
\end{tabular}

Table 4. Radioactivity of amino acids products of $\left(1-{ }^{14} \mathrm{C}\right)$ TNT transformation by fungi strains

\begin{tabular}{|c|c|c|c|c|c|c|c|}
\hline \multirow[b]{2}{*}{ Strain } & \multirow{2}{*}{$\begin{array}{l}\text { Radioactivity of } \\
\text { amino acids in \% }\end{array}$} & \multicolumn{6}{|c|}{ Distribution of radioactivity in individual amino acids, in \% } \\
\hline & & $\begin{array}{l}\text { Phenylal- } \\
\text { anine }\end{array}$ & $\begin{array}{l}\text { Glutamic } \\
\text { acid }\end{array}$ & Tyrosine & Arginine & $\begin{array}{l}\text { Asparag- } \\
\text { inic acid }\end{array}$ & Serine \\
\hline Mucor sp.T1-1 & 27.8 & 27.4 & 19.3 & 17.5 & 13.6 & 11.5 & 10.7 \\
\hline Trichoderma sp. N2-6 & 22.6 & 24.3 & 16.6 & 18.7 & 18.5 & 11.5 & 10.4 \\
\hline Aspergillus niger N2-2 & 10.2 & 38.9 & 14.7 & 12.8 & 11.4 & 11.8 & 10.4 \\
\hline
\end{tabular}




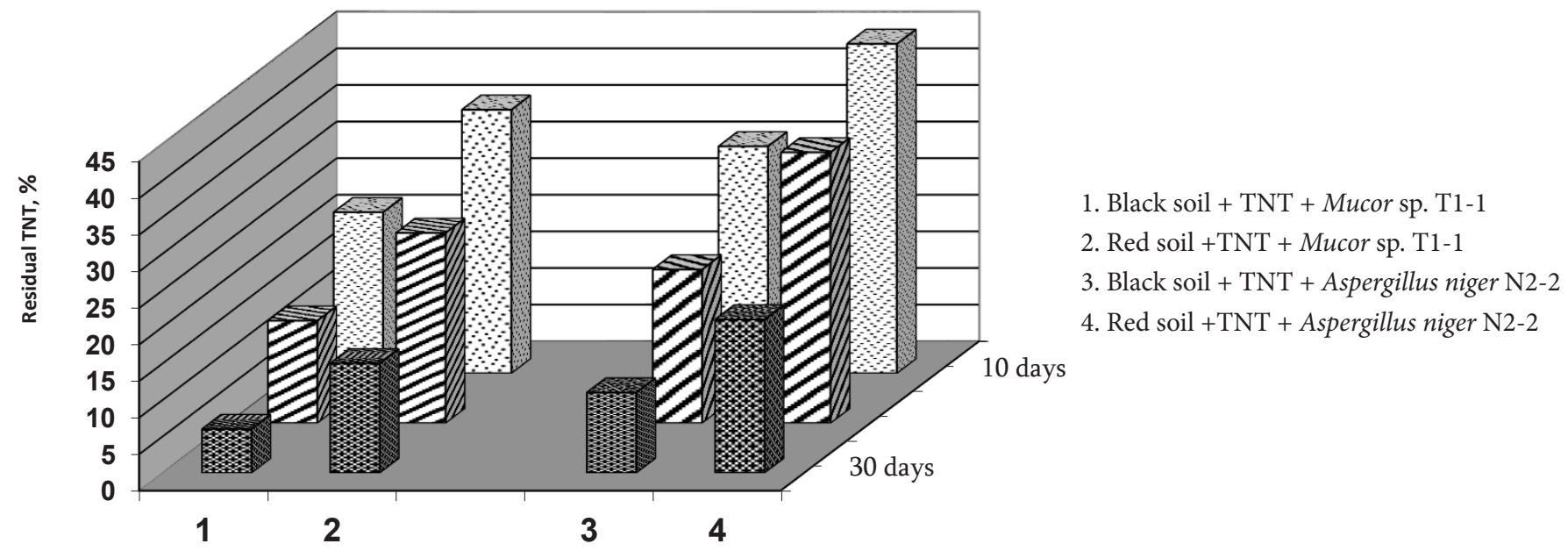

Figure 5. Degradation of TNT in black and red soils by microscopic fungi.

Table 5. Changes of CFU of fungi introduced into TNT-contaminated soils

\begin{tabular}{|l|c|c|c|c|c|}
\multirow{2}{*}{ Strain } & \multirow{2}{*}{ Soil types } & \multicolumn{4}{|c|}{ CFU per g of soil } \\
\cline { 3 - 6 } & & Initial amount & 10 days later & 20 days later & 30 days later \\
\hline \multirow{2}{*}{ Mucor sp. T1-1 } & Black soil & $7,5 \times 10^{5}$ & $9,5 \times 10^{6}$ & $6,5 \times 10^{5}$ & $3,5 \times 10^{4}$ \\
\hline \multirow{2}{*}{ Aspergillus niger N2-2 } & Red soil & $7,5 \times 10^{5}$ & $5,5 \times 10^{5}$ & $3,5 \times 10^{4}$ & $2,3 \times 10^{4}$ \\
\cline { 3 - 6 } & Black soil & $8,5 \times 10^{6}$ & $4,5 \times 10^{7}$ & $5,5 \times 10^{5}$ & $6,5 \times 10^{4}$ \\
\hline & Red soil & $8,5 \cdot 10^{6}$ & $4,5 \times 10^{6}$ & $3,5 \times 10^{5}$ & $4,5 \times 10^{4}$
\end{tabular}

Development of fungi introduced in black and red soils proceeds differently. In black soils, CFUs of introduced cultures are increased by single-order on the $10^{\text {th }}$ day of cultivation, and then are gradually reduced. In red soils, CFUs of introduced strains are reduced on the $10^{\text {th }}$ day. It might be explained that black soils are richer by organics and presumably the existing organic matter promotes to overcome the stress caused by action of the toxicant. Maximal decrease of TNT takes place during the first 10 days (by 64-72\%) and the amount of residual TNT makes up only $6-15 \%$ for the last 20 days. It should be mentioned that degradation of TNT is more intensive in black soils. Experiments conducted under laboratory conditions showed that introduction of active strains effectively decreases the concentration of TNT in soil. To compare this data with field conditions $0.3 \mathrm{~m}^{2}$ of black and red soils were artificially contaminated by $1 \mathrm{mM}$ TNT per kg of soil; the depth of contamination $-30 \mathrm{~cm}$.

One of the main goals of the project was testing TNT transformation potential of Aspergillus niger N2-2 and Mucor sp. T1-1 through their introduction directly into contaminated non sterile soils. Certain amount of TNT was introduced into both types of soils (sterile and non sterile). In order to exclude utilization of TNT by local indigenous microorganisms the same amount of TNT was introduced into the sterile soils In addition, culture liquid of selected strains with biomass (grown under deep cultivation conditions), together with the TNT were introduced into the soil (each strain was grown under optimal growth conditions). Thus, the following variants were tested for each type of soil and each fungi strain:

- Sterile soil + TNT (considered as control)

- Nonsterile soil + TNT

- Nonsterile soil +TNT + microorganism

After 40 and 100 days of incubation, both the amount of residual TNT and that of CFU in terms of $1 \mathrm{~g}$ of dry soil were determined in each sample. The experimental data showed that the number of local (indigenous) microorganisms reduced after 40 and 100 days; it was caused by the fact that part of local microorganisms could not undergo adaptation to the introduced toxicant. While at the first stage(introducing selected strains), the amount of microorganisms existing in the soil slightly decreased, but later, returned again to the initial amount or in some cases, even insignificantly exceeded it (Table 6 and Fig. 6).

As seen from the above presented data, the level of TNT assimilation in soil by local microorganisms makes $40-50 \%$, and in case of additional introducing of strains-destructors reaches $80 \%$.

\section{Discussion}

In spite of some suppositions on different genera strains activities directed to TNT degradation experimental results showed a picture. As shown in Fig. 2, strains of microscopic 


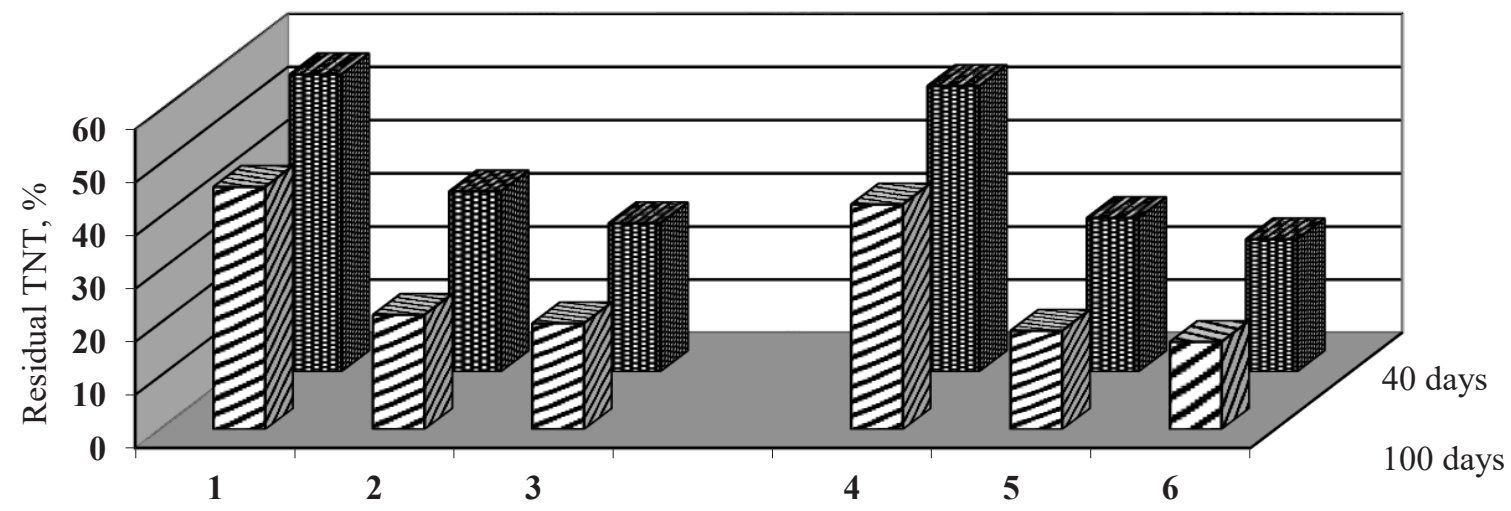

1. Red soil (nonsterile soil) + TNT

4. Black soil (nonsterile soil) + TNT

2. Red soil (nonsterile soil) $+\mathrm{TNT}+$ Aspergillus niger N2-2

3. Red soil (nonsterile soil) + TNT + Mucor sp. T1-1

5. Black soil (nonsterile soil) $+\mathrm{TNT}+$ Aspergillus niger $\mathrm{N} 2-2$

6. Black soil (nonsterile soil) + TNT + Mucor sp. T1-1

Figure 6. Degradation of TNT by microorganisms under natural modeling conditions.

Table 6. Changes of CFU of introduced and indigenous fungi in TNT contaminated soils under natural modeling conditions

\begin{tabular}{|l|c|c|c|}
\hline \multirow{2}{*}{ Test variant } & \multicolumn{3}{|c|}{ CFU of fungi per 1g of soil } \\
\cline { 2 - 4 } & $\begin{array}{c}\text { At the moment of } \\
\text { inoculation }\end{array}$ & 40 days later & 100 days later \\
\hline Red soil (sterile soil) + TNT & 0 & 0 & 0 \\
\hline Red soil (nonsterile soil) + TNT & $3.8 \times 10^{6}$ & $1.2 \times 10^{6}$ & $1.3 \times 10^{5}$ \\
\hline Red soil (nonterile soil) + TNT + Aspergillus niger N2-2 & $5.4 \times 10^{6}$ & $3.9 \times 10^{5}$ & $4.9 \times 10^{6}$ \\
\hline Red soil (nonsterile soil) + TNT + Mucor sp. T1-1 & $1.9 \times 10^{6}$ & $7.2 \times 10^{5}$ & $1.3 \times 10^{6}$ \\
\hline Black soil (sterile soil) + TNT & 0 & 0 & 0 \\
\hline Black soil (nonsterile soil) + TNT & $6.5 \times 10^{6}$ & $4.7 \times 10^{5}$ & $3.2 \times 10^{5}$ \\
\hline Black soil (nonsterile soil) + TNT + Aspergillus niger N2-2 & $5 \times 10^{6}$ & $8.8 \times 10^{5}$ & $5.7 \times 10^{6}$ \\
\hline Black soil (nonsterile soil) + TNT + Mucor sp. T1-1 & $1.9 \times 10^{6}$ & $7.0 \times 10^{5}$ & $2.4 \times 10^{6}$ \\
\hline
\end{tabular}

fungi - Trichoderma sp. N2-6, Trichotecium sp.S1-6 and Mucor sp. T1-1, maximally utilized trinitrotoluene.A bit less activity was expressed by the strain Trichotecium sp.S1-6, which also should be related to highly active TNT degrading strains. The strains Aspergillus niger N2-2 and Aspergillus niger K3-5 also utilized TNT by average intensity, as compared with 9 selected strains. In spite of higher activities expectations, strains Trichoderma sp. N2-6 and Mucor sp.T1-1exposed less but still significant activities of TNT utilization. The strainsdistinguished by the best growth in the presence of high concentrations of TNT have the best TNT transformation potential. It should be underlined that the 4 strains - Mucor sp. T1-1, Aspergillus niger K3-5, Trichoderma sp. N2-6 and Aspergillus niger N2-2 were isolated from adjacent to military grounds and their activity comparatively could be explained by long time adaptation of strains to the toxicants containing environment.

The strains - Aspergillus niger K3-5, Aspergillus niger N2-2 and Trichoderma sp. N 2-6 maximally conducted biotransfor- mation of TNT for 72-78 h of cultivation. For the strain $\mathrm{Mu}$ cor sp. T1-1, optimal duration of cultivation time was 96-104 hours.Such a long time transformation of TNT is required by the complicated metabolism pathway of this contaminant. As it has been shown the initial microbial conversion of TNT undergoes reducing reaction in particular microorganisms, conduct transformation of TNT into the following intermediate metabolites: azoxytetranitrotoluene, aminodinitrotoluene and hydroxylaminodinitrotoluene (15).

The identification of individual low molecular weight compounds formed as a result of biodegradation of (1-14C)- TNT by the strains of microscopic fungi having a high detoxification ability are shown in Table 2. Formation of labeled amino acids, directly indicate on TNT carbon skeleton utilization by selected fungi strains. Carbon atoms of 1-14C-TNT are converted by microscopic fungi in a way that first carbon atom of TNT mainly participates in synthesis of organic acids. Radioactive label of $1-14 \mathrm{C}$-TNT is mostly found in fumaric acid which is one of the 
main products of benzene microbial transformation and easily undergoes further transformations.

As a result of consecutive enzymatic reactionsof TNT proceeding under the action of microscopic fungi, individual carbon atoms of this compound are involved in intracellular processes of metabolic and energy exchange. It can be concluded that the carbon skeleton of the TNT molecules adsorbed by the test cultures undergoes deep degradation. The initial stage of this process must be the reduction of the nitro groups, after which the aromatic ring of the TNT molecule is used in the biosynthesis of aromatic amino acids. After reduction of the main part of the assimilated toxicant molecules, their oxidation follows which leads to removal of the amino groups and cleavage of the aromatic ring, and as a result organic acids are formed as standard cell metabolites. As a result it might be concluded that TNT is completely decomposed under theactionof microscopic fungi and carbon atoms are involved in metabolic process typical for these taxonomic group of microorganisms (2). The introduction of strains- Aspergillus niger N2-2 and Mucor sp. T1-1 improves the potential of soils directed to TNT degradation that confirms high destructive activity of these strains in natural conditions.

\section{Final Remarks}

As a result of selection microscopic fungi kept in the collection at Durmishidze Institute of Biochemistry and Biotechnology, 107 strains assimilating 2,4,6-TNT belonging to the different genera - Aspergillus, Penicillium, Mucor, Fusarium, Trichoderma, Rhizopus, Botrytis, Alternaria, Cladosporium and Trichothecium have been revealed. The strains have been isolated from the polluted areas adjacent to the military grounds and industrial waste waters. The most actively TNT is degraded by strains representing genera Aspergillus, Mucor and Trichoderma. Optimal cultivation conditions for highly active strains, destructors of TNT have been revealed.

In order to establish degradation of TNT carbon skeleton, transformation products of $\left(1-{ }^{14} \mathrm{C}\right)$-TNT by fungi strains $\mathrm{Mu}$ cor sp. T1-1, Trichoderma sp. N2-6 and Aspergillus niger N2-2 have been studied. Formation of radioactive organic and amino acids indicates on deep degradation of TNT. It was found that carbon atoms of $1-{ }^{14} \mathrm{C}-\mathrm{TNT}$ assimilated by microscopic fungi mainly participate in synthesis of organic acids (70-90\%) and amino acids (10-30\%).

Remediation level of TNT-contaminated soils treated by the most active strains Aspergillus niger N2-2 and Mucor sp. T1-1 have been studied under laboratory and field conditions. Cultivation of the above mentioned strains under laboratory conditions in sterile black and red soils for 30 days at $30^{\circ} \mathrm{C}$ allowed to decrease the content of TNT in black soil to the residual, and in red soil - to $15 \%$; cultivation of Aspergillus niger N2-2 decreased the amount of TNT in black soil to 11 and in red soil - to $21 \%$. Under the field conditions, TNT degradation level in contaminated soils by naturally existing microflora during 100 days was equal to $40-50 \%$, and in case of introduction additionally fungal strains, TNT-destructors, reached $80 \%$. Finally, the data analysis indicate that TNT is deeply degraded under the action of fungal strains and carbon atoms of this toxic compound are involved in regular metabolic process of fungal strains.

\section{References}

1. Yateem A, Balba MT, Al-Awadhi H, El-Nawawy AS. White-rot fungi and their role in remediating oil-contaminated soil. Environment International1998; 24:181-187.

2. EPA. Health Effects Summary Tables. Annual FY-91. Prepared by thy office of health and Environmental Assessment, Environmental Criteria Remedial Repose. Washington, D. C. OERR 9200. 1991; a.6-303 (91-1). NTIS PB91-921199.

3. Freeman RA, Hileman FD, Noble RW, Schroy JM. In: J.H. Experiments on the mobility of 2.3.7.8-tetrachlorodibenzo-p-dioxin at Times Beach, Missouri ed. // Solving Hazardous Waste Problems, ACS Symposium 1987; Series Num. 338.

4. Yanders AF, Orazio CE, Puri RK, Kapila S. On translocation of 2.3.7.8 -tetrachlorodibenzo-p-dioxin: time dependent analysis at the Times Beach experimental site. Chemosphere 1989; 19(1-6):429432.

5. Lee S, Lee SY, Shin KS. Biodegradation of 2,4,6-trinitrotoluene by White-Rot Fungus.Mycobiology 2009; 37(1): 17-20.

6. Solyanikova IP, Baskunov BP, Baboshin MA, Saralov Al, Golovleva LA. Detoxification of high concentrations of trinitrotoluene by bacteria. Appl. Biochem. Microbiol.2012; 48:21-27

7. Bayman P, Radkar GV. Transformation and tolerance of TNT $(2,4$, 6-trinitrotoluene) by fungi. Int. Biodeter. Biodegr.1997; 39: 45-53.

8. Fomin GS, Fomin AG. Soil. Monitoring on quality and ecologic safety in accordance with international standards. Moscow, VNII standard), 2001; 86.

9. Waksman SA. Soil fungi and their activities. Soil., Sci 1916; 2(1) : 103-105.

10. Litvinov MA. Determinant of microscopic soil fungi. - Leningrad: Nauka, 1967, 303.

11. Dovid M. Moulds, Their Isolation, Cultivation, and Identification. University of Toronto Press. 1981; 114.

12. Frank M. Dugan.The Identification of Fungi. The American Phytopathological Society St. Paul, Minnesota U.S.A. 2006; 176.

13. Sunahara Gl, Rodidoux PY, Havari J, Thiboutot S, Ampleman G, Renoux AY. Ecotoxicological methods to assess thehazardous effects of energetic substances at contaminated sites. In: Contaminated Soil - Proceedings of the $7^{\text {th }}$ International FZK/TNO Conference on Contaminated Soil, Leipzig, Germany, 2000;.2: 886-887.

14. Oh B, Sarath G, Shea PJ, Drijber RA, Comfort SD. Rapid spectrophotometric determination of 2,4,6-trinitrotoluene in a Pseudomonas enzyme assay. J Microbiol Methods 2000; 42(2):149-158.

15. Parrish FW. Fungal transformation of 2,4-dinitrotoluene and 2,4,6-trinitrotoluene (TNT). Appl Environ Microbiol 1977; 34:232233. 